\title{
A Estética na Philosophica
}

Ana Rita Ferreira $\boldsymbol{I}^{\mathbf{1}}$
(Centro de Filosofia da Universidade de Lisboa / ILOS, Universitetet i Oslo)

Entre os grandes ramos filosóficos, a estética é o mais recente e também o mais sinuoso no que toca às fronteiras do seu campo de estudos. É assumindo essa sinuosidade que aqui apresentamos os artigos publicados ao longo dos 25 anos da revista Philosophica no âmbito na estética.

Sendo um âmbito caracteristicamente propiciador de diálogos transversais, não é de admirar o peso que a estética sempre teve na história deste periódico, tendo sido árdua a tarefa de triar os artigos que lhe concernem² ${ }^{2}$ Muitos são os textos directamente respeitantes ao âmbito da estética, mas muitos são também os textos híbridos ou os que se socorrem de hermenêuticas estéticas para abordar temas que as suas tradicionais fronteiras deixariam de fora.

O núcleo daquilo que se considera ser a estética teve a sua primeira delimitação no séc. XVIII, com Baumgarten. Além de lhe cunhar o nome, o filósofo abriu para a estética uma via mais ampla do que aquela que viria a ser adoptada nas universidades europeias até inícios do séc. XXI. Tem sido essa via ampla da estética que a revista Philosophica segue desde

1 a.r.ferreira@ilos.uio.no

2 Ficará de fora a menção aos inúmeros textos pertinentes à esfera da estética que integraram os separadores Recensões, Leituras e Dissertações. Também eles atestam o grande interesse que este ramo sempre despertou no círculo académico nacional, desde que a revista iniciou a sua tiragem. 
a sua fundação em 1993, adiantando-se à actual tendência expansionista de uma estética que não se subsume à filosofia da arte, nem se fica pelas tradicionais teorias do belo. Não é, pois, de estranhar que a revista tenha dedicado um número especial a Baumgarten (Philosophica 44, Novembro de 2014), por altura da celebração dos 300 anos do nascimento do filósofo. Este número especial contou com oito artigos aprofundando temáticas cuja pertinência ultrapassou o mero âmbito histórico do pensamento baumgartiano ${ }^{3}$.

Além do número especialmente dedicado ao pai da estética enquanto disciplina filosófica, a revista conta com outros números temáticos enquadráveis no âmbito em questão. É o caso do número duplo de 2002 (Philosophica 19/20), votado à estética e à filosofia da arte que, na esteira da grande procura do mestrado homónimo, dava a conhecer a produção decorrente dessa nova linha de estudos na Faculdade de Letras da Universidade de Lisboa. Esse número provava já a compreensão da estética na senda ampliada que Baumgarten inaugurara e que foi injustamente abandonada pelas sequentes gerações de filósofos. Nele estava já representada a diversidade dos discursos sobre a filosofia da arte e sobre a estética, sem consubstanciação dos dois domínios. Temáticas como a sensibilidade e o corpo, o carácter significante dos objectos de arte, as suas instâncias de legitimação ou as qualidades estéticas da natureza marcam presença neste número, a par da análise de diversos momentos importantes da história da disciplina nos últimos duzentos anos e de artigos cuja abordagem filosófica toma como ponto de partida pregnâncias resultantes do encontro com a

\footnotetext{
3 Tratando-se da referência a textos que integram o mesmo número temático, dispensaremos, nesta e nas seguintes notas, as informações relativas ao número e data da publicação, sendo elas já mencionadas no corpo do texto. Bengerd Juul Thorsen, "Baumgarten's Meditationes as a commentary on Horace's Ars Poetica", 9-25; Tomoe Nakamura, "The cognitive and ethical scope of 'confusion' in Baumgarten's aesthetics", 27-46; J. Colin McQuillan, "Baumgarten on sensible perfection”, 47-64; Maximiliano Hernández Marcos, "El sentido interno, tópica natural de la invención en A. G. Baumgarten”, 65-91; Dirk Michael Hennrich, "Alexander Gottlieb Baumgartens Ästhetik und die Desastres de la guerra des Francisco de Goya", 93-106; Gualtiero Lorini, "The Origins of the Transcendental Subjectivity: on Baumgarten's Psychology", 107-126; Courtney D. Fugate, "Alexander Baumgarten on the Principle of Sufficient Reason", 127-147; Adrian Switzer, "The traditional form of a complete science: Baumgarten's Metaphysica in Kant's Architectonic of Pure Reason”, 149-164. Este número conta ainda com a tradução dos Prolegómenos da Estética de Baumgarten, feita por Ana Rita Ferreira. A tradução surge acompanhada pela apresentação do texto latino de 1750 .
} 
obra de artistas plásticos ${ }^{4}$.

Em 2010, um novo número temático dava destaque a propriedades centrais da experiência estética - o som e a cor (Philosophica 36). $\mathrm{O}$ primeiro artigo deste volume segue a perspectiva pictórica de Manlio Brusatin, tendo a cor azul como pano de fundo para um estudo etiológico sobre a dimensão espaciotemporal da pintura ${ }^{5}$. Para tal, são convocadas as obras de pintores como Rafael, Kandinsky, Yves Klein, Mark Rothko e Gerhard Richter. Domingos Rebelo, Borba Vieira e Egon Schiele são outros artistas sobre os quais recaem abordagens filosóficas. Os dois primeiros, a propósito de elementos simbólicos que poderão enquadrar-se na açorianidade, enquanto conceito poético capaz de exprimir a relação do sujeito com o espaço geográfico e cultural em questão ${ }^{6}$. Kandinsky é estudado quanto à concepção de "vibração interior", teorizando-se as questões do tempo, da liberdade e da vida ${ }^{7}$. Por seu turno, o texto dedicado a Schiele estabelece uma ponte entre a obra pictórica do artista e os escritos de Robert Musil, numa estratégia comparatista centrada no filosofema da diferença,

4 João Maria André, “As artes do corpo e o corpo como arte”, 7-26; José M. Miranda Justo, "Os faróis dos automóveis (Sobre linguagem e arte em sentido extra-moral)", 27-41; Carlos Gonçalves, "a filosofia da arte, a filosofia da arte de massas, e o exílio da avaliação", 43-56; José Quaresma, "A gravidade do consenso sob suspeita”, 57-67; Ângela Delfino, "Estética e paisagem: algumas referências legais", 69-85; Leonel Ribeiro dos Santos, "O espírito da letra: sobre o conflito entre Fichte e Schiller a respeito da linguagem da filosofia e da natureza do estético", 87-114; Maria de Lurdes Pequito, "Hegel: sobre o prosaico e o poético", 115-129; Ana Anahory, "Letras do sublime: Lyotard e Derrida", 131-154; Inês Barahona de Almeida, "A cegueira na origem do desenho. Jacques Derrida em Mémoires d'aveugle", 155-176; Victor Silva, "Estética e ética em Monroe C. Beardsley", 177183; Eduardo Pellejero, "J. L. Borges: los precursores de Kafka. Por una historiografía literaria no historicista", 185-202; Américo Marcelino, "Imagem e representação", 2032015; Ana Mantero, "Contraponto. Klee e Kandinsky: diálogos numa terra fértil”, $217-$ 240; José Artur Ramos, "No traço dos traços do nosso rosto", 241-250; Manuel Pedro Ferreira, "Juízo estético e filologia musical: em torno de um cancioneiro polifónico do século XV", 251-278; Cristina Beckert, "Da obliteração: reflexões levinasianas sobre a obra de Sosno", 279-289; Cristiana Veiga Simão, "As ideias embaraçosas. A natureza da razão e a sua relação com a experiência do sublime”, 293-309.

5 Ana Cravo, "Pequena história do azul", 9-23. Embora não pertencente a este número temático, note-se um outro artigo sobre o tema das cores, que analisava o seu conteúdo simbólico e modo como o seu uso havia sido legislado no Antigo Regime: António Manuel Hespanha, "As cores e a instituição da ordem no mundo do Antigo Regime”, Philosophica 27 (2006), 69-86.

6 Gabriela Castro, "Simbologia da açorianidade na pintura de Domingos Rebelo e de Borba Vieira", 45-54.

7 José Miranda Justo, "Kandinsky e o Espírito. Tempo, liberdade e vida na concepção kandinskyana de 'vibração interior'”, 67-83. 
enquanto abertura à relação ${ }^{8}$. Duas das teorias filosóficas acerca da natureza da obra de arte são discutidas também neste número, num artigo sobre a definição proposta por Levinson e sobre o critério de identificação que Carroll lhe contrapôs ${ }^{9}$. A música marca presença através de dois artigos. O primeiro centra-se no diálogo entre a linguagem verbal e a musical durante o séc. XIX, através de exemplos retomados dos escritos teóricos de Berlioz, Schumann e Wagner ${ }^{10}$. É dada especial atenção à influência que o último exerceu sobre Kierkegaard através do artigo "De l'Ouverture", em 1841. O segundo texto sobre música deste número temático explora como as filosofias do processo recorrem à metáfora musical enquanto todo indivisível formado por instantes que só no seu conjunto compõem o significado. Para tal, revisita-se Whitehead e Bergson ${ }^{11}$.

Outros são os números da revista Philosophica onde encontramos perspectivas sobre a arte e a partir dos quais se pode aceder a uma compreensão histórica das suas alterações. Note-se o número 14 (Novembro de 1999), com um artigo sobre a transição do paradigma platónico para o aristotélico na concepção artística europeia do séc. XVI e de como o artista e filósofo português Francisco de Holanda a antecipara ${ }^{12}$. Veja-se ainda o número 7 (Abril de 1996), com um texto sobre as ideias clássicas de arte e de natureza, tal como surgem na retórica portuguesa setecentista ${ }^{13}$, ou o

8 Katia Hay, "A diferença como revelação na obra de Egon Schiele e Robert Musil”, 55-66.

9 Paula Mateus, "A questão da natureza das artes: as teorias históricas de Levinson e Carroll”, 85-91.

10 Elisabete M. de Sousa, "Richard Wagner: Leitmotiv e música dramática", 25-44. Já em 2002, a música havia sido abordada num artigo que a define como objecto fenomenológico dependente de parâmetros escritos e de um enquadramento hermenêutico que tornam indissociáveis o raciocínio filológico e o juízo estético: Manuel Pedro Ferreira, "Juízo estético e filologia musical: em torno de um cancioneiro polifónico do séc. XV", Philosophica 19/20 (2002), 251-278. Em 2006, encontramos um outro artigo acerca do relativismo na avaliação de execuções musicais: António Lopes, "Relativismo na avaliação das execuções musicais", Philosophica 27 (2006), 121-134. De notar ainda que um dos trabalhos vencedores do Prémio Joaquim Cerqueira Gonçalves foi também consagrado à temática em questão: Hugo Luzio, "Sonicismo tímbrico e instrumentalismo: Uma disputa ontológica”, Philosophica 46 (2015), 145-162.

11 Maria Teresa Teixeira, “A música e o devir”, 93-105. Não muito longe das filosofias do processo, conta-se a proposta de Bachelard, "La Rythmanalyse", cuja tradução foi publicada no número 31, antecedida por um estudo acerca da sua recepção em Portugal: Rodrigo Sobral Cunha, "A Filosofia do Ritmo Portuguesa: da Monadologia Rítmica de Leonardo Coimbra a Lúcio Pinheiro dos Santos e a Ritmanálise”, Philosophica 31 (2008), 161-191.

12 António Moreira Teixeira, "Francisco de Holanda e a arte em perspectiva", 99-116.

13 Pedro Calafate, “Arte e Natureza no século XVIII em Portugal”, 47-63. 
primeiro número da revista Philosophica (Abril de 1993), com um ensaio sobre a importância do mito na filosofia da arte nietzschiana ${ }^{14}$. No número 16 (Novembro de 2000), cabe a perspectiva de John Ruskin, através da apresentação da sua proposta de educação artística em Lectures on Art ${ }^{15}$. Também o número 45 (Abril de 2015) é relevante, já que nele encontramos o texto de Georg Simmel "L'art pour l'art", de 1941, traduzido e apresentado por Adriana Veríssimo Serrão ${ }^{16}$. A organicidade da concepção simmeliana descreve a arte como artefacto que ultrapassa a sua naturalidade espaciotemporal e se eleva a "mais que vida" pelo seu intangível conteúdo espiritual.

A obra de Simmel sobre Rembrandt serve, no número 42 (Novembro de 2013), como ponto de partida para um estudo sobre o auto-retrato, no qual, uma vez mais, a questão da unidade e da sua inserção na corrente múltipla da vida marca presença. O papel que a interioridade e a individualidade assumem no auto-retrato é central para esta abordagem que articula a efemeridade existencial com os conceitos de duração e de continuidade propiciadas pelas obras de arte ${ }^{17}$. De um âmbito mais abrangente do que o da arte, o número dedicado a Simmel percorre também questões que diríamos próprias da filosofia da cultura. Desde logo, encontramos leituras que exploram uma metaperspectiva da reflexão simmeliana centrada na pregnância dos paradoxos ${ }^{18}$ e nas suas alegorias ${ }^{19}$.

Dois anos mais tarde, um novo número temático traz à cena a questão da cultura na sua índole trágica, colocando Simmel ao lado de Nietzsche e Benjamin (Philosophica 46, Novembro de 2015). Também aqui as tensões entre o uno e o múltiplo são o pano de fundo diante do qual se desenrolam as múltiplas expressões da vida subjectiva, em marcha desfasada com os seus produtos - formas acabadas, segmentadas e petrificadas. A tragicidade de tal desfasamento que marca a cultura contemporânea, tal como é encontrada nos escritos de Nietzsche, Simmel e

14 Leonel Ribeiro dos Santos, "O retorno ao mito. Nietzsche, a música e a tragédia", 89-111.

15 Paula Mateus, “A função social da arte em Lectures on Art de John Ruskin”, 81-102.

16 Georg Simmel, “L'art pour l'art”, intr. e trad. Adriana Veríssimo Serrão, 127-135.

17 José Artur Ramos, "O auto-retrato como consciência da nossa vida”, 93-105. Note-se que a questão do auto-retrato havia já sido aprofundada no número 19/20, pelo mesmo autor —Idem, "No traço dos traços do nosso rosto", Philosophica 19/20 (2002), 241-250 — e através de uma leitura derridiana, no artigo de Inês Barahona de Almeida, "A cegueira na origem do desenho - Jacques Derrida em Mémoires d'Aveugle", Philosophica 19/20 (2002), 155-176.

18 Teresa Sousa Fernandes, "Figuras transgressivas da união dos contrários", 37-44.

19 Carlos Fortuna, “Georg Simmel: as cidades, a ruína e as novíssimas metrópoles”, 107-123. 
Benjamin, permite um substrato de resiliência pedagógica cuja aplicação articula a memória e as suas formas de narratividade, numa senda contracorrente à da razão funcional, do autoritarismo e do antropocentrismo das sociedades hodiernas ${ }^{20}$. A este nível, a análise especifica-se no tópico da "memória involuntária" proposto por Benjamin em 1929, no texto "A imagem de Proust". A rememoração e o seu papel nas condições de percepção do homem contemporâneo são o ponto de partida para um ensaio sobre a tradição, a experiência e a visão históricas e sobre como estas se repercutem nas artes e na literatura ${ }^{21}$. Um outro conceito que na obra de Benjamin assume contornos de resistência face à oposição "mito" e "história" é o do "silêncio trágico"22. A visão do mundo nietzschiana em $O$ Nascimento da Tragédia é abordado neste número a partir da interpretação de Thomas Mann e da sua leitura simbólica acerca da montanha mágica, provando a fecundidade dos diálogos entre a filosofia e a $\operatorname{arte}^{23}$. Na mesma senda, está o artigo dedicado à consolidação oitocentista da pintura paisagista e do seu contributo para a definição do conceito "paisagem", ao qual não foi alheio o ramo filosófico que dela se ocupa ${ }^{24}$.

A filosofia da paisagem é, aliás, um dos núcleos fortes da revista Philosophica ao nível das transversalidades propiciadas pela estética. Dois artigos franquearam a entrada deste domínio filosófico na revista: na edição dupla de 2002 (Philosophica 19/20), um dos textos abordava os conceitos de "estética" e de "paisagem" nos ordenamentos jurídicos internacional ${ }^{25} \mathrm{e}$, em Abril de 2004, o número 23 contava com um artigo acerca do papel que a categoria da paisagem assume na reflexão estética contemporânea, analisando não só o modo como certas teorias se debruçaram sobre a questão da definição desse conceito, mas também as especificidades da apreciação

20 Teresa M. L. R. Cadete, “A perda do fio narrativo. Sobre a insustentabilidade do trágico na contemporaneidade", 9-17.

21 Maria João Cantinho, "A teia de Penélope e o anel da tradição. Cultura e rememoração na obra de Walter Benjamin”, 79-95.

22 Ernani Chaves, "O 'silêncio trágico' - Walter Benjamin entre Franz Rosenzweig e Friedrich Nietzsche", 67-78.

23 Carlos João Correia, “A luz branca da neve: Nietzsche e Thomas Mann”, 31-38.

24 Dirk Michael Hennrich, "Tragische Dispositionen der Moderne. Stimmung und Aura im Wandel des Landschaftsbegriffs", 19-30.

25 Ângela Delfino, "Estética e Paisagem - Algumas referências legais", 69-85. De notar que neste número há ainda um artigo que apresenta uma leitura sobre a relação entre a estética a ética no pensamento de Monroe C. Bearsdley, por Victor Silva (177-183). 
estética da paisagem e as suas relações com o posicionamento ético ${ }^{26}$. O número 29 (Abril de 2007) veio consolidar a abertura propiciada por este artigo seminal, estando o seu escopo inteiramente votado às estéticas da natureza. $\mathrm{O}$ editorial explicava então a diferença entre o modelo clássico de reflexão filosófica acerca do sentimento de admiração pela beleza natural e a amplitude do questionamento contemporâneo, na sua subtracção à hegemonia da filosofia da arte e consequente renúncia ao antropocentrismo que subordinava o domínio do natural ao do cultural. De mãos dadas com a ética, as novas direcções da estética da natureza rumam contra a sua instrumentalização, na senda trilhada por autores como Ronald W. Hepburn, Theodor Adorno, Rosario Assunto, Allen Carlson ou Arnold Berleant.

O primeiro artigo deste número temático aprofundava o afastamento do natural em relação às projecções antropomórficas e às concepções mecanicistas $^{27}$. Ainda que com matizes muito próprias, esse afastamento do paradigma mecânico em direcção ao orgânico é encontrado na filosofia da arte nietzschiana ${ }^{28}$ e prenunciado na articulação entre estética e teleologia da terceira Crítica kantiana, interpretada neste número à luz da consciência ecológica contemporânea ${ }^{29}$. A complexidade de tal consciência não só viabiliza, como pede, a existência de narrativas hermenêuticas que cruzam aspectos socio-culturais e ecossistémicos determinados pelo rumo multívoco da autopoiesis natural ${ }^{30}$. A dicotomia da pregnância vital da paisagem, como experiência estética, e a visão trágica do homem moderno, afastado da natureza, marcam a análise feita à obra timoneira de Georg Simmel, "Filosofia da Paisagem", de 1913 ${ }^{31}$. Essa mesma dicotomia repercute-se na defesa da validade do conceito de paisagem como "identidade estética do lugar", ao nível da arquitectura paisagista ${ }^{32}$. Num outro artigo, a génese da arquitectura paisagista em Portugal é usada para contextualizar o próprio conceito contemporâneo de paisagem, tal como a Escola de Arquitectura Paisagista Portuguesa o entende. O texto esquematiza ainda os paradigmas

\footnotetext{
26 Adriana Veríssimo Serrão, "Filosofia e Paisagem. Aproximações a uma categoria estética”, 87-102.

27 Cristina Beckert, "A estética do invisível na natureza", 7-17.

28 Clademir Luís Araldi, "Organismo e arte na filosofia de Nietzsche”, 35-47.

29 Leonel Ribeiro dos Sants, "Kant e a ideia de uma estética da natureza”, 19-34.

30 Andreia Saavedra Cardoso, "Paisagem e complexidade ecológica. A necessidade das narrativas", 49-64.

31 Paulo Frazão Roberto, "A harmoniosa pregnância vital da paisagem natural em Georg Simmel”, 65-85.

32 Maria Franscisca Machado Lima, "Estéticas da paisagem e arquitectura paisagista”, 87-102.
} 
a que correspondem os modos de representação e construção da paisagem $^{33}$. O contributo de Gonçalo Ribeiro Telles é explícito tanto neste texto, como no que se lhe segue, acerca da concretização da vertente teórica no espaço do Jardim da Fundação Calouste Gulbenkian ${ }^{34}$. Fazendo juz à irmandade que a estética ambiental tem com a ética ambiental, este número conta com um contributo que se centra na responsabilidade antropocósmica, de cariz jonasiano, promovendo o sentido de um rumo concertado entre o homem e a natureza ${ }^{35}$. A secção "Documento" remata este número com a tradução de um texto de Petrarca, "Carta do Monte Ventoso", tido como uma das primeiras narrativas escritas acerca da exploração e apreciação de um lugar natural ${ }^{36}$. Um prolongamento da revisitação histórica ao nível da estética é feito no número 30 (Novembro de 2007), através de uma leitura antropológica do sentimento da natureza em Kant, Feuerbach e Simmel ${ }^{37}$.

$\mathrm{Na}$ intersecção entre o cultural e o natural, o jardim propicia também leituras filosóficas, tendo sido abordado logo no número 4 (Novembro de 1994) a propósito das teorias e da arte dos jardins setecentistas portugue$\operatorname{ses}^{38} \mathrm{e}$ tendo constituído tema para o número 32 deste periódico (Novembro de 2008). O artigo de abertura do número dedicado ao jardim explora-o precisamente como filosofema, percorrendo os princípios estéticos subjacentes a diferentes concepções da Modernidade e quadros de referência contemporâneos como a ontologia, a teleologia e a ética do cuidado, que vieram ampliar a categoria filosófica do jardim $^{39}$. Muitos são os teóricos convocados neste número para tal abordagem filosófica, desde Agostinho — aqui em diálogo com o escritor suiço Philippe Jaccottet ${ }^{40}$ —, passando por Simmel e pela influência da sua Stimmung para a estética musical de Jankélévitch ${ }^{41}$, ou por Bergson e Rosario Assunto ${ }^{42}$. O Parque dos Poetas,

33 Manuela Raposo Magalhães, "Paisagem: Perspectiva da Arquitectura Paisagista", 103-113.

34 Aurora Carapinha, "O Jardim da Fundação Calouste Gulbenkian: a poética da materialidade e da temporalidade", 115-123.

35 Lourenço Zancanaro, "Ética ambiental e responsabilidade antropocósmica”, 125-143.

36 Francisco Petrarca, "Carta do Monte Ventoso", trad. Paula Oliveira e Silva, 145-154.

37 Adriana Veríssimo Serrão, "Sentimento da Natureza e Imagem do Homem: Kant, Feuerbach e Simmel”, 203-224.

38 Pedro Calafate, “Teoria e arte dos jardins no séc. XVIII em Portugal”, 127-140.

39 Adriana Veríssimo Serrão, "Da essência do jardim. Aproximações a uma categoria filosófica", 5-13.

40 Ana Rita Ferreira, "Agostinho e Jaccottet: o jardim como lugar de transcendência”, 15-30.

${ }^{41}$ Joana Quaresma Luís, "Vida, arte e paisagem. Jankélévitch leitor de Simmel”, 31-51.

42 Lavínia Pereira, "Diegese da durée bergsoniana na filosofia da natureza de Rosario Assunto", 53-67. 
em Oeiras, é alvo de uma leitura hermenêutica centrada na analogia com o texto poético e na especificidade de elementos como a árvore e a folha, na sua acepção de semióforos ${ }^{43}$. $\mathrm{O}$ artigo que encerra este dossier temático situa ao nível da estética contemporânea uma articulação entre elementos éticos relevantes no jardim japonês e a filosofia taoista que lhe está na base, convocando afinidades com a teleologia kantiana a propósito do mundo natural ${ }^{44}$.

Outros foram os números temáticos dedicados à filosofia da natureza, embora sem o protagonismo da vertente estética (Philosophica 47: Thinking Nature Today, Abril de 2016; Philosophica 48: Thinking Nature Today II, Novembro de 2016) e outros foram também os números que, não sendo temáticos, acolheram contributos que se inscrevem no âmbito da estética da natureza. No número 39 (Abril de 2012), encontramos um artigo que defende a relevância dos valores estéticos ambientais para a preservação de espaços naturais, colocando em íntima relação beleza natural e ética ambiental ${ }^{45}$.

O número seguinte (Philosophica 40: Ética Animal e Ética Ambiental, Novembro de 2012) marcava uma mudança na estrutura editorial da revista, ao ser o primeiro número dirigido pela Professora Adriana Veríssimo Serrão. Essa mudança constituiu, na verdade, uma continuidade em termos programáticos face às anteriores direcções - pela mesma exigência de qualidade, originalidade e relevância para o debate actual das abordagens propostas - , todavia ampliando o corpo editorial com consultores externos de renome, apostando na internacionalização da própria revista, reforçando a sua indexação e inaugurando a sua transposição para uma plataforma digital, que disponibiliza, em livre acesso após um ano de carência, os conteúdos publicados também em papel. Não é despiciendo, nos dias que correm, este detalhe da manutenção paralela da edição impressa. Neste número de charneira, a estética ambiental estava também representada por dois artigos: o primeiro, situado num perfil de contiguidade com a ética e com a política ambientais ${ }^{46}$; o segundo, propondo a tríade composta pela estética, pela ética e pela ciência para as hermenêuticas da paisagem, integrando na primeira componente não apenas categorias positivas e negativas específicas de uma estética natural, como também

\footnotetext{
43 Isabel Matos Dias, "O jardim: retorta de alquimista", 67-76.

44 Tiago Mesquita Carvalho, "O jardim japonês na estética da natureza contemporânea”, 77-91.

45 Maria José Varandas, "Ética natural e ética ambiental”, 131-139.

46 Jorge Marques da Silva, "Perspectivas antropocêntricas e ecocêntricas da estética ambiental: contributos para a sustentabilidade", 45-56.
} 
elementos de articulação com categorias estéticas aplicáveis quer às narrativas sobre a paisagem, quer ao próprio cruzamento entre o natural e $o$ cultural $^{47}$.

O já citado número 42, dedicado a Simmel, integra um texto sobre a génese da Stimmung, explorando a síntese entre subjectividade e objectividade, da qual decorre a integradora impressão da simultaneidade entre imanência e transcendência, tal como lemos em "Os Alpes". A via estéticometafísica da Stimmung em "Os Alpes", escrito por Simmel em 1911, estaria presente dois anos mais tarde na sua "Filosofia da Paisagem"48. A actualidade de Simmel para o domínio da estética poderá assumir-se para lá das suas considerações sobre a arte e sobre a experiência dos espaços naturais, já que a sua fenomenologia acerca dos espaços urbanos, das grandes cidades históricas italianas e da ruína propiciam ao autor reflexões também elas de âmbito estético, que não foram descuradas no número $42^{49}$.

A cidade presta-se, com efeito, a tematizações estéticas, tais como as que encontramos num dos primeiros números da revista (Philosophica 4: A cidade, Novembro de 1994), que a tomou como mote, por altura da nomeação de Lisboa a capital europeia da cultura desse ano. O ecletismo do número em questão abriu portas a abordagens sobre os jardins portugueses no séc. XVIII ${ }^{50}$ e sobre a presença fundadora da cidade como motivação do discurso poético ${ }^{51}$. De modo mais transversal e bastante mais superficial, a estética percorre os textos deste número a propósito das suas intersecções com a política e a ética das topologias urbanas ${ }^{52}$; da identidade metropolitana e das impressões que notáveis como Munzer, Cervantes, Linck, Byron, Costizan ou Beckford nos deixaram sobre Lisboa ${ }^{53}$; da apropriação e identificação do espaço urbano pelos seus diferentes usuários ${ }^{54}$; da educação filosófica do cidadão na paideia ateniense e do ideal de perfeição que

\footnotetext{
47 António Queirós, "Campos de Deméter: da impossibilidade de separar a ciência, a ética e a estética na hermenêutica da paisagem", 69-94.

48 Teresa Dugos, “A experiência estético-metafísica de 'Os Alpes'. Sobre a génese da Stimmung em Georg Simmel”, 23-36.

49 Carlos Fortuna, "Georg Simmel: as cidades, a ruína e as novíssimas metrópoles", 107-123.

50 Pedro Calafate, "Teoria e arte dos jardins no séc. XVIII em Portugal”, 127-140.

51 Helena Carvalhão Buescu, "Metrópolis, ou mais uma visita do Sr. Scrooge (A poesia de António Nobre)", 59-67.

52 Carlos Henrique do Carmo Silva, “A cidade - Máquina de Fazer Felicidade”, 7-46.

53 Jorge Gaspar, "Da observação de Lisboa: Alguns apontamentos", 47-58.

54 Teresa Barata Salgueiro, "Repensar a cidade face a novos desafios", 69-80.
} 
perpassa a democracia grega ${ }^{55}$. $\mathrm{O}$ tema imiscui-se ainda na esquematização da ideia da Europa em Rousseau ${ }^{56}$ e na relação entre a convivência intersubjectiva e o modo de estar comunitário dos habitantes da cidade, cujo cosmopolitismo constitui berço de renovação cultural ${ }^{57}$.

Outro núcleo temático que se prestou a pontos de vista estéticos, ou sobre a própria estética, foi privilegiado no número dedicado ao cruzamento entre filosofia e literatura (Philosophica 9, Abril de 1997). Com uma cautelosa contextualização centrada na questão da linguagem natural/linguagem científica, o conjunto de textos compilados para este número versam sobre a fenomenologia literária dos textos filosóficos ${ }^{58}$, sobre a legitimidade do uso da literatura no processo de transmissão da filosofia ${ }^{59}$; sobre a vertente literária de filósofos como Heidegger, Platão e Aristóteles ${ }^{60}$; sobre a relação entre poesia e filosofia na obra de Antero de Quental ${ }^{61}$; sobre a filosofia da literatura em Levinas ${ }^{62}$; sobre a análise do significado simbólico da novela de Thomas Mann "A Montanha Mágica", através do âmbito das interpretações acerca das metáforas ${ }^{63}$; sobre a dimensão comunicativa da obra ${ }^{64}$; sobre a ampliação da noção de referência e a aplicabilidade da semântica extensional na explicação das subtilezas de cariz estético ${ }^{65}$. Fora deste número temático, a revista Philosophica publicou muitos outros

55 José Trindade dos Santos, “A cidade dos homens. Polis, educação e democracia”, 81-98.

56 Carlos Morujão, "Mito e história nas meditações de Rousseau sobre o destino da Europa", 109-126.

57 Viriato Soromenho-Marques, "Notas sobre o ambiente urbano", 141-147.

58 Manuel Cândido Pimentel, "Elementos para uma fenomenologia literária do texto filosófico", 7-31.

59 Fernanda Henriques, "É legítimo o uso da literatura na transmissão da filosofia?", 145-167.

60 Irene Borges-Duarte, "Filosofia e estilo literário em Heidegger e em Platão"; José Trindade dos Santos, "Platão, o Amor e a Retórica"; João Paisana, "Discurso Científico e poético na Filosofia de Aristóteles", 33-57.

${ }^{61}$ Leonel Ribeiro dos Santos, “'Ideia poética' e 'Ideia filosófica'. Sobre a relação entre poesia e filosofia na obra de Antero de Quental”, 95-121.

${ }^{62}$ Cristina Beckert, "O Outro literário: a filosofia da literatura em Levinas", 133-143.

${ }^{63}$ Carlos João Correia, “Thomas Mann e a Montanha Mágica”, 123-131.

64 Manuel J. Rodrigues, “A obra como facto comunicativo”, 189-205.

${ }^{65}$ Carmo d'Orey, “A Identidade de Vénus ou as vantagens da extensionalidade”, 169-187. Da mesma autora, destaca-se um outro artigo, por seu turno centrado na diferença acerca das ideias de progresso e acordo ao nível das artes e das ciências. Tal diferença é, segundo a autora, devida às características semânticas e sintácticas dos respectivos sistemas simbólicos: Idem, “Arte e Ciência: Acordo e Progresso”, Philosophica 3 (1994), 71-84. 
textos com hermenêuticas filosóficas acerca de elementos literários ${ }^{66}$, textos sobre as relações entre texto literário e texto filosófico ${ }^{67}$, além de artigos sobre as afinidades entre escritores e filósofos ${ }^{68}$.

A introdução do horizonte criativo na contrução de sentido tem também pertinência na esfera da estética. A este nível, é possível encontrarmos vários textos publicados na revista Philosophica que, embora não se filiem directamente no ramo filosófico que nos ocupa, apresentam discussões que seriam proveitosas para as abordagens estéticas. É o caso dos que versam

66 Cristina Beckert, "Hölderlin e o 'Retorno Natal'”, Philosophica 3 (1994), 37-50; Carlos João Correia, "Kafka e as metamorfoses da lei", Philosophica 7 (1996), 125-139; Viriato Soromenho Marques, "Walden: The 'Art of Living"”, Philosophica 40 (2012), 41-44; Tiago Mesquita de Carvalho, "A paisagem no Diário de Miguel Torga", Philosophica 42 (2013), 163-181; José Pedro Serra, “Agamemnon, en Attendant Godot: Da heróica palavra trágica ao trágico silêncio do exílio”, Philosophica 30 (2007), 183-202; Eduardo Pellejero, "J.L. Borges: los precursores de Kafka. Por una historiografia literária no historicista”, Philosophica 19/20 (2002), 185-202.

67 Maria Luísa Ribeiro Ferreira, "O texto literário como propedêutica do texto filosófico", Philosophica 6 (1995), 125-131; Isabel Matos Dias, "Vestígios do mundo. Literatura e filosofia em Merleau-Ponty”, Philosophica 10 (1997), 29-44; Fernanda Henriques, “A penumbra tocada de alegria: a razão poética e as relações entre filosofia e literatura em Maria Zambrano", Philosophica 11 (1998), 49-61; José António Leite Cruz de Matos Pacheco, "A dialéctica da verdade e do sentido: Subsídios para o situar de uma estética em Weil", Philosophica 13 (1999), 57-89; Silvano Peloso, "Poética e Filosofia da memória na lírica de Camões", Philosophica 15 (2000), 65-78; Maria de Lurdes Pequito, "Hegel: sobre o prosaico e o poético", Philosophica 19/20 (2002), 115-129; António Rocha Martins, "Filosofia e literatura. O paradigma bonaventuriano", Philosophica 27 (2016), 87-115; João Maria André, “A Filosofia, o teatro do mundo e o mundo do teatro: pelos labirintos da identidade”, Philosophica 30 (2007), 113-120; Nuno Filipe Ribeiro, "Os livros filosóficos inacabados de Pessoa. Problemas e critérios para a publicação dos escritos filosóficos de Pessoa", Philosophica 38 (2011) 165-174.

68 Ana Maria Bijóias Mendonça, "Vergílio Ferreira e María Zambrano", Philosophica 23 (2004), 69-85; Irene Borges-Duarte, “A ontologia trágica de Sófocles e a sua tradução em Hölderlin e Heidegger”, Philosophica 11 (1998), 111-132; José Luís Garcia, “Afinidades electivas entre Georg Simmel e Natália Correia. Para o estudo da recepção de Simmel em Portugal", Philosophica 42 (2013), 125-139; Adelino Braz, "Nietzsche et Pessoa: La métaphore du semblant", Philosophica 21 (2003), 79-99; José António Matos Pacheco, "O platonismo de Marcel Proust: Tempo, memória, sentido", Philosophica 27 (2006), 107-119. 
sobre a metáfora ${ }^{69}$, o mito $^{70}$, o erotismo ${ }^{71}$ ou sobre a constituição de imaginários específicos ${ }^{72}$.

Abordámos já a presença de diferentes perspectivas sobre a obra de arte na história da revista Philosophica, tendo ficado por elencar quer os contributos que directamente se ocuparam da análise de perspectivas acerca do âmbito estético para lá das fronteiras da arte - com excepção dos artigos dedicados a Baumgarten e a Simmel —, quer os contributos que desenvolvem perspectivas originais na via ampla da estética. Neste último grupo, é de salientar o contributo singularíssimo de Cristiana Veiga Simão, prematuramente desaparecida, com três artigos. Pela clarividência e actualidade em época de sociabilidades virtuais, o primeiro texto merece ser revisitado vinte e dois anos após a sua publicação. Nele, a autora alertava para o perigo do enfraquecimento das experiências estéticas e da sua partilha no mundo contemporâneo, com inevitáveis consequências para as esferas da ética e da política, bem como para a ideia de pertença a uma tradição. Por um lado, esse enfraquecimento tem lugar através da substituição do homo aestheticus pelo da figura do "público" e do "espectáculo multimediático". Por outro lado, ele é também a consequência inevitável das estratégias hipercríticas e desconfiadas face à produção de sentido pela via da estética, que tentam forçar uma tradução aniquiladora e desconstruções do sentido do seu carácter originário, sobreanalisando-o, buscando o seu fundamento e reduzindo-o à expressão da comunicabilidade dos seus

69 João Paulo de Oliveira Cruz Mendes, "Indivíduo e realidade: de Simmel a Kracauer", Philosophica 27 (2006), 135-155. Pode também ler-se acerca da centralidade da metáfora na espiritualidade e no pensamento de S. Boaventura em António Rocha Martins, "Filosofia e literatura. O paradigma bonaventuriano", Philosophica 27 (2016), 87-115.

70 Veja-se por exemplo, Markus Gabriel, "Metafísica e mitologia", Philosophica 27 (2006), 53-67; Mafalda Blanc, "Desconstrução e retomação. Heidegger e a demanda do originário", Philosophica 45 (2015), 57-68.

71 Carlos João Correia, "Eros e nostalgia. Ensaio sobre Freud”, Philsophica 3, (1994), 7-18; Paulo Borges, "A experiência erótica em Leonardo Coimbra”, Philosophica 3 (1994), 19-36; Maria José Vaz Pinto, “A recepção ou a invenção ficiniana do 'amor platónico"”, Philosophica 14 (1999), 51-84.

72 Manuela Ribeiro Sanches, "Cães canibais, homens simiescos, harmonia da criação. Representações da alteridade na Alemanha do século XVIII", Philosophica 15 (2000), 17-32; Paulo Borges, "Do(s) outro(s) mundo(s) da visão ao novo mundo da razão: Viagem iniciática, des(en)cobrimento(s) e u-topia”, Philosophica 15 (2000), 47-63; Leonel Ribeiro dos Santos, "As metamorfoses da luz, ou a retórica da evidência na filosofia cartesiana", Philosophica 8 (1996), 17-36; José Barata-Moura, "Peso, pêsame, pesadelo - para um sopesamento (não saudosista) da saudade", Philosophica 10 (1997), 3-27; Adelino Cardoso, "O sonho na Medicina do Renascimento", Philosophica 14 (1999), 147-164. 
contextos de ocorrrência. A impossibilidade de deslocar a dimensão do sentir para o domínio público sem o perverter compreende-se na sua temporalidade lenta, selectiva e interior, avessa a socializações impostas pelo exterior ou "pela simples vontade retórica de comunicar" 73 . O segundo texto de Cristiana Veiga Simão publicado na Philosophica, interroga acerca do estatuto e do significado do corpo humano na cultura contemporânea, defendendo a necessidade do reconhecimento do seu valor estético, ético e antropológico. Muitas das reflexões presentes neste artigo evidenciam uma intuição daquilo que futuramente seria desenvolvido no âmbito da somaestética, ou somaesthetics, tal como foi cunhado por Richard Shusterman este sub-ramo da estética em 1996, apenas um ano antes da publicação do artigo de Cristiana Veiga Simão ${ }^{74}$. O terceiro texto — resultante de dois estudos escritos pela autora durante a fase de preparação da sua tese de doutoramento - versa sobre a razão e a sua relação com a experiência do sublime ${ }^{75}$. A referência à Crítica da Faculdade de Julgar de Kant é aqui incontornável como também o é para muitos dos outros artigos já referidos ${ }^{76}$.

Ao nível dos contributos que directamente se ocuparam da análise de perspectivas acerca do âmbito estético para lá das fronteiras da arte, há ainda a salientar um conjunto de artigos que aprofunda tópicos como a contemplação humana e o prazer divino em Aristóteles; a articulação do conceito estético agostiniano numerus com o conceito anselmiano rectitu$d o$; ou as ressonâncias estéticas do carácter mediador do Verbo na teoria

73 Cristiana Veiga Simão, "Imagem, palavra e responsabilidade”, Philosophica 6 (1995), 119-124.

74 Idem, "Mens sana in corpore sano? Reflexões sobre o enigma do corpo", Philosophica 9 (1997), 207-223. Note-se que o tema do corpo, agora quanto às suas valências expressivas, voltaria a ter lugar na Philosophica, numa abordagem mais antropológica, a propósito de uma leitura do livro de Helmuth Plessner Rire et pleurer, de 1941: Adriana Veríssimo Serrão, "Opacidade e limite na antropologia de Helmuth Plessner", Philosophica 38 (2011), 107-120. Ao nível da filosofia da arte, a temática do corpo é central para um dos textos vencedores do Prémio Prof. Doutor Joaquim Cerqueira Gonçalves 2013: Tomás Neves Castro, "Um corpo em presença. Uma aproximação a Marina Abramović", Philosophica 42 (2013), 189-198.

75 Idem, "As Ideias Embaraçosas. A natureza da razão e a sua relação com a experiência do sublime", Philosophica 19/20 (2002), 293-309.

76 Dos que ainda ficaram por referir, note-se Ubirajara Rancan de Azevedo, "Consideraciones filológicas a propósito del 'genio' en Kant”, Philosophica 42 (2013), 147-161 e Vítor Moura, "Velocidade e acordo: o carácter metafórico das ideias estéticas", Philosophica 24 (2004), 43-64. A mencionar é também o trabalho vencedor do Prémio Prof. Doutor Joaquim Cerqueira Gonçalves 2016: Raoul Andrei Marian, "Descoberta do númeno? Um paradoxo na estética kantiana”, Philosophica 48 (2016) 119-129. 
anselmiana e sua repercussão na filosofia bonaventuriana ${ }^{77}$. Também autores como Fichte, Schiller, Kierkegaard, Nietzsche, Lyotard, Derrida, Luc Ferry, Mario Perniola e Martin Seel são convocados a propósito de quadros conceptuais próprios da estética na sua via ampla de compreensão ${ }^{78}$. Só esta via está em conformidade com os modelos filosóficos não catequéticos que a revista Philosophica procurou acolher desde o seu primeiro número.

77 Respectivamente, Manuel Cruz Ortiz de Landázuri, “Contemplación humana y placer divino en Aristóteles", Philosophica 41 (2013), 193-209; Ana Rita Ferreira, "Dos sentidos à verdade suprema. Uma leitura comparada entre Agostinho e Anselmo", Philosophica 34 (2009), 93-101; Filipa Afonso, "Para uma estética da criação. Deduções bonaventurianas da teoria do verbo em Anselmo", Philosophica 34 (2009), 145-156.

78 Leonel Ribeiro dos Santos, "O espírito da letra: sobre o conflito entre Fichte e Schiller a respeito da linguagem da filosofia e da natureza do estético", Philosophica 19/20 (2002), 87-114; Elisabete M. de Sousa, "Sobre o estético em Kierkegaard", Philosophica 45 (2015), 107-124; Manuel João Pires, "Nietzsche e o cavalo. Prelúdio a uma justificação estética da existência", Philosophica 16 (2000), 117-134; Ana Anahory, "Leituras do sublime: Lyotard e Derrida", Philosophica 19/20 (2002), 131-154; Adriana Veríssimo Serrão, "Pensar o sentir de hoje. Mutações da sensibilidade estética", Philosophica 17/18 (2001), 79-102. 